\title{
Sniffing the City: Issues of Sousveillance in Inner City
}

\section{London.}

\begin{abstract}
The article reflects on a series of workshops run by the art/media/hacktivist collective Deptford.TV in collaboration with the CUCR at Goldsmiths in 2009-2010 and in 2012. The aim of such workshops was to create short films using hacked CCTV material. Participants, equipped with digital video signal receivers, were led through the city by incoming surveillance camera signals. Receivers cached surveillance camera signals and made these spaces visible. The material was then stored on a shared video platform and re-shuffled in personal narratives and montages of the city.

Hackers and media artists call it 'sousveillance' and frame it as a critique of the 'panopticon society'. I will investigate such issues in a forthcoming work (Cardullo 2013). In this article I argue that this practice unveils an unusually realistic portrait of inner-city London: working-class people in their everyday work activities. My contention is that this portrait is particularly valuable due to bolstering narratives of gentrification which often hides those activities. In addition, there are made invisible by the presumed end of manual work.

The concluding part is inherently reflexive and evaluates this emerging and ethically controversial practice of video recording. It asks to what extent it can become a useful tool for urban studies, visual sociologists and media artists. My conclusion is that the exercise is certainly a moment of self-discovery for the urban stroller, who - while practicing a sort of heroic immersion in inner city London - paradoxically becomes a watcher of a life scene fabricated at 'safe' distance, a middle way between an urban ethnographer and the flâneur.
\end{abstract}

\section{Paolo Cardullo}

\section{Ph.D. Visual Sociology}

\section{Goldsmiths - University of London}

I have recently been awarded my Ph.D. in Visual Sociology, which I discussed with prof. Douglas Harper and dr. Alison Rooke. The thesis, supervised by prof. Caroline Knowles and prof. David Oswell, investigates affective geographies of gentrification in inner-city London. I am currently a post-doc teaching fellow at the CUCR, Goldsmiths. I own second-hand laptops running Linux and promote workshops on Zotero and other Free and Open Source Software. 


\section{The City from Below (as it has never been seen)}

The article narrates and critically engages with a series of 'video sniffing' workshops conducted by an art and media collective ${ }^{1}$ through the streets of Deptford, aiming at documenting its regeneration. The starting point of our workshops, as well as of this article, is that this densely populated South East London neighbourhood is facing an advanced process of private-capital-driven urban change. However, this happens mostly on previously unoccupied land or derelict spaces and, so it is maintained, it does not induce displacement of resident population. Others label this process as 'newbuild gentrification' (Davidson and Lees 2005), taking into account its indirect and exclusionary effects. ${ }^{2}$ I want to use this crucial contention as a background to my analysis of the 'video sniffing' workshops.

While public rhetoric insists on the beneficial character of inner-city gentrification with its 'trickle-down effects' (Lees 2008), ${ }^{3}$ the academic debate has recently been focussing on what we can call the 'denial of displacement' (see Slater 2006). On the one hand, gentrification gets reframed as a neutral process. It assumes the organic end of manual labour and (therefore) of urban working-classes. It produces no displacement of people, but rather their 'replacement' (Hamnett 2003). On the other hand, middle-class lifestyles have been taken as normative. This dramatic process of material and cultural urban change is therefore refashioned by the 'urban cool', hipsters, organic cafés, luxury live-work pads, 'yummy mummies', and so on. Gentrification is connoted as a beneficial 'rising tide'. The problem with this explanation is that 'the academic nobility assumes its middle-class cultural practices as to be good for everyone', as Allen (Allen 2008) has it. Wacquant has caustically termed this

1 Deptford.TV in collaboration with SPC.org and the Centre for Urban and Community Research at Goldsmiths (2009 - 2010, 2012).

2 See Marcuse (1985) for a discussion on these issues.

3 Gentrification is seen as an incremenntal demographic movement which would create the critical mass for new services such as transports and schools (Silverman, Lupton, and Fenton 2006). 
academic turn in urban studies as the 'ultimate paradox of the gentrification of gentrification' (Wacquant 2008). In other words, working-class people are made invisible twice. Firstly, by simply denying their numerical relevance for statistical purposes and, secondly, by sweeping under the carpet their own classed ways of working and living in the city.

I would argue that the first challenge for critical urban scholars is therefore to make visible people and practices that escape representational mapping. Data, in the forms of numbers and statistical surveys, are powerful abstractions that can make workingclass lives and their daily efforts disappear like in an experienced magician's hat-trick. The embeddedness and groundedness of visual representations can instead help to reposition people's lives in their 'flesh and blood'. Despite the complex and problematic ways in which visual representations come into being, they can help to recast those lives in the social landscape they belong to and which they help to fabricate (see Knowles and Sweetman 2004; Becker 2002). In this respect, methods adopted in order to make the city known are not just an exercise of research practice, rather they substantiate a critical theoretical stance towards gentrification.

In this article I maintain that the content of the video captured from the lower-end CCTV technology is very relevant simply because it unveils a realistic portrait of inner city London with its working-class people and their everyday practices of work. My argument draws on direct participation of three workshops in psychogeography and video 'sniffing' (Deptford.TV \& CUCR 2009 - 2010, Deptford.TV 2012), on critical content analysis of the raw footage produced, and on interviews with participant artists/researchers. 


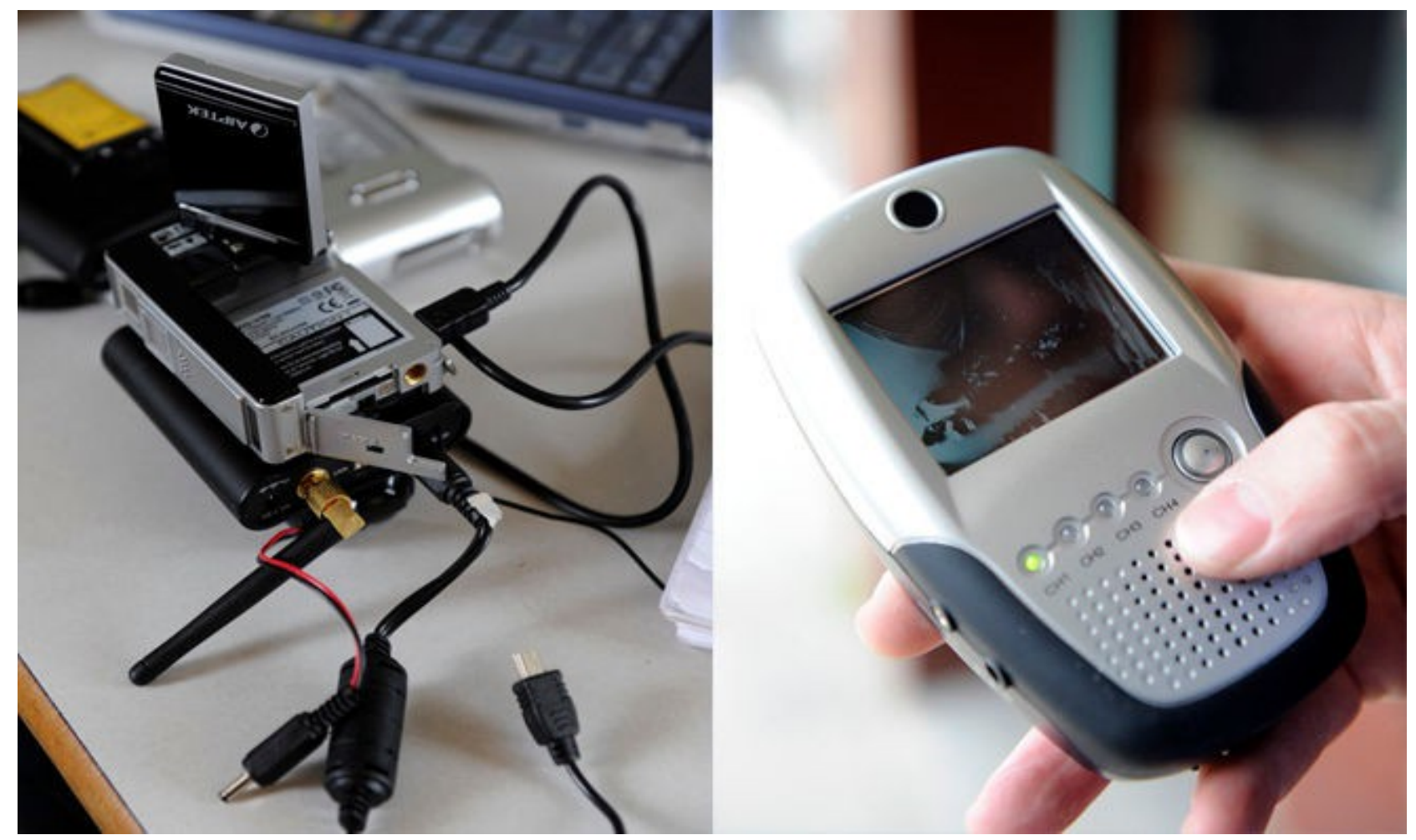

Fig. 1 Recording and sniffing devices (Deptford.TV).

Deptford.TV is an open and collaborative platform for media artists and network activists, conceived by dr. Adnan Hadzi (Dept. of Media, Goldsmiths). Since 2005 Deptford.TV has been experimenting with art and media methods in order to increase participation and sharing of research practices. With the Centre for Urban and Community Research, it launched a series of practice-based workshops on collaborative filming and CCTV 'sniffing' with the aim 'to store, share and re-edit the documentation of the urban change of South East London'. ${ }^{4}$ Participants, equipped with digital video receivers, cached surveillance camera signals from public and private spaces which were previously invisible (Fig. 1). Following the uncertain signals and the glitches from the electronic waves captured by the device, they were led through inner city Deptford. Some of the questions that workshop participants asked were: What

4 For further information on Deptford TV projects and platform, see this interview to Hadzi: http://tinyurl.com/ccwt3zi 
happens to the huge amount of CCTV recorded material? Who owns it? Can we recycle any small discarded part of such a vast pile of 'digital rubbish' (Gabrys 2011)?

When the groups returned to the lab, the digital material we collected was stored and catalogued in order to make it effectively editable for film-making purposes. That is, a detailed database with raw data was made functional with a system of classification by tagging. We then added the location where the clips were taken in the form of GPS tagging. The digital archive can therefore be accessed and modified by registered users who become active participants, rather than being simply passive viewers. Paradoxically, those loose fragments of urban flow were again ordered, dated and put on the city map.

\section{Sniffing the City}

Our workshops included some amazing video clips of family run businesses or socalled 'corner shops' (Fig. 4-6). Shop assistants, hairdressers, take-away attendants, halal butchers, all became clearly visible in-between the erratic glitches of the uncertain video signals. What is most incredible is that they are simply practising their work in their usual workspaces. ${ }^{5}$ The first merit of our 'sniffing' excursions has been the ability to make visible some of the many manual working practices of inner city Deptford. These are too often hidden by bolstering discourses on urban change or disappear in narratives which presume the end of manual work (Stallabrass, 1997; Strangleman, 2008).

I contend that there is an incredible realist energy in the raw clips captured by the sniffing device. CCTV acted like a fly-on-the-wall camera, resembling long shots of the

5 It is time to introduce some hacked video clips. The West-African hairdresser and the halal butchers are available here: http://edit.deptford.tv/node/204; the Asian-run nail shop is here: http://edit.deptford.tv/node/229; the Chinese take-away here: http://edit.deptford.tv/node/197 
best realist cinema verité (for instance Fig 2-3). It is worthy recalling here that various realist avant-garde movements had a main problem in representing life at the level of the everyday, simply because the very stuff which makes it is so banal and 'uninteresting'. If nothing happens, why bother to represent it? The quotidian is the signifier par excellence of the realistic impulse, but it is also the residuum of all meaningful activities. It is made of both the material reality and the impossibility to account for it (Lefebvre, cited in Margulies 1996). Especially in the visual arts, the 'insignificant' event resists representation. And yet, where else can we find the workings of power and the daily strategies put in place in order to cope, if not in the spaces of everyday life, of labour and leisure?

Images, however, are not 'realist' because they simply resemble reality so closely. They also need to be framed in the context and moment of their production. This is the second merit of the 'video sniffing' workshops. These were in fact set up partly with the aim to investigate the regeneration of Deptford. This has been experiencing sustained second and third wave gentrification ${ }^{6}$, as most of inner London (Davidson 2009). Its working-class residents are undergoing unprecedented levels of 'exclusionary' and 'indirect' displacement ${ }^{7}$ due to speculation in the residential housing market, to creation of new shops and services which foreground a different set of consumers' preferences and lifestyle, and to building of new luxury riverside estates in the north part of the borough, directly facing the river Thames (Davidson and Lees 2005). Among the main peculiarities of Deptford, there is its vanishing history of its centrality in the industrial economy of the docks, its fading post-colonial landscape and the vast, but often misrepresented, council housing population. Les Back, who has done much research and methodological experimentation in the streets of this South East London borough,

6 Second wave concerns an establishing of the pioneering wave of middle-class residents in the existing residential housing stock, while the third wave sees newly build constructions mostly on ex-industrial sites and brownfields.

7 See Marcuse 1985 and Slater 2009 for a more detailed discussion on these terms. 
summarises these trends in a very effective way:

From the 1950s [Deptford] became a place of settlement for citizen migrants from the Caribbean, largely from Jamaica. Additionally, south London provided a home for Turkish Cypriots during the 1970s, Vietnamese refugees in the 1980s and, from the 1990s, West African migrants from Nigeria and Ghana. In the twenty-first century, the presence of eastern European migrants from Poland and Lithuania and South American migrants from Brazil and Columbia have added further cultural textures to the area. (Back 2009)

The continuous influx of new waves of migrants becomes visible around the busy High Street shopping facilities and market stalls. Les Back beautifully describes this interplay between people, place and objects: 'It's the stuff of and for the everyday, and it has an ordinary, unpretentious feel, serving a mostly local clientèle of African-Caribbeans, Chinese and white British' (Back and Lyon 2012).

I insist on these aspects because this dense, messy and extremely diverse urban space undergoing gentrification prompted the workshops and, irremediably, determined their visual outcomes. To put it simply, the analysis of the media content generated by the combined practices of walking and 'sniffing' cannot be taken out of this almost overwhelming context. The streets and people of Deptford were in fact not just the frame within which our observation happened, but they played a primary role. What is more, due to the peculiar medium we adopted, they happened to be even the involuntary producers of such narratives.

The nail parlour, the hairdresser's, the butcher's, etcetera, are trading places but also places of interaction, where people meet and connect on the ground of everyday 'banal' practices. This undermines the prevalent idea substantiates by mainstream accounts that link gentrification to a benevolent 'social mixing'. Put it differently, the way in which 'cultural quarters' become desirable, up-and-coming and fashionable (Keith 
2005) might not produce the same outcome in terms of social mixing as the daily mingling among markets stalls, within community schools, at streets corners, and in council estates, that is, in the inner city 'contact zones'. ${ }^{8}$
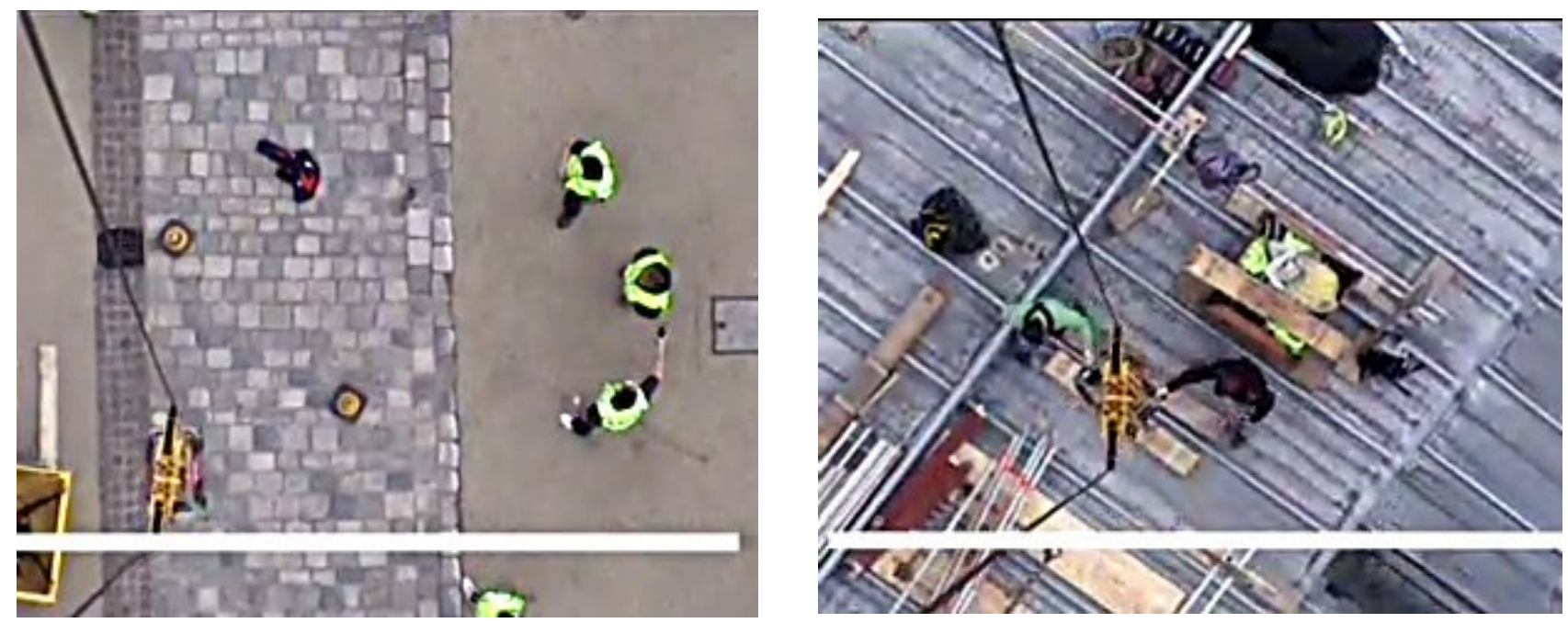

Fig. 2-3 Crane over workers at the Royal Naval College, Greenwich.



Fig. 4 Worker and till in halal butcher's, Deptford.

8 These are the places in which, according to Stuart Hall, a slow and inexorable 'multicultural drift' rises (Hall and Back 2009) 
I understand that there are some crucial technology related issues that have contributed to determine the quality of the recorded material, its exclusive aesthetics and, ultimately, the content of the films. The digital receivers used for the workshops are widely available from electronic stores at very reasonable price. This has almost certainly caused the 'ghostly' appearances in the uncertain glitches of the electronic waves captured by the devices (see below). Moreover, the cheapest digital video surveillance systems have generally a low level of protection. Surveillance company Cop Security, for instance, is well known to video sniffing practitioners for sending out open wireless signals. As one of the media project organisers admits: 'The best areas for wireless cameras are small businesses who have gone for cheap CCTV installs in their shops and offices; wireless cameras are also popular in homes, gardens and garages'. ${ }^{9}$ I would argue that this was not a limit of our workshops but rather offered participants an incredible opportunity.

The predominance of family-run shops in the hackers' reach gave the film clips their peculiar flavour. The texture of this migrant and working-class place, that is Deptford, started to come out in the scenes captured from their CCTV cameras. Rather than the power structure covered by the higher end of the security industry, participants were able to 'film' the invisible city of daily social practices of mundane shopping and services. Instead of hacking the 'panopticon' of the sanitised city, ${ }^{10}$ the workshops were able to foreground the cultural diversity and vibrancy of working-class social practices of living and trading in inner city Deptford. I would argue that this is the strength and the novelty of our experimental approach. This in fact puts an involuntary emphasis on ordinary practices of surveillance, affordable security and daily aspects of work that working-class effectively do. Its outcome is even more poignant when juxtaposed to the

9 http://gearbox.mediashed.org/?section=tutorials\&action=view\&id=120 10 See Cardullo 2013, forthcoming. 
normative novel of gentrification as a cultural process 'lifting everybody up' (Allen, cited).

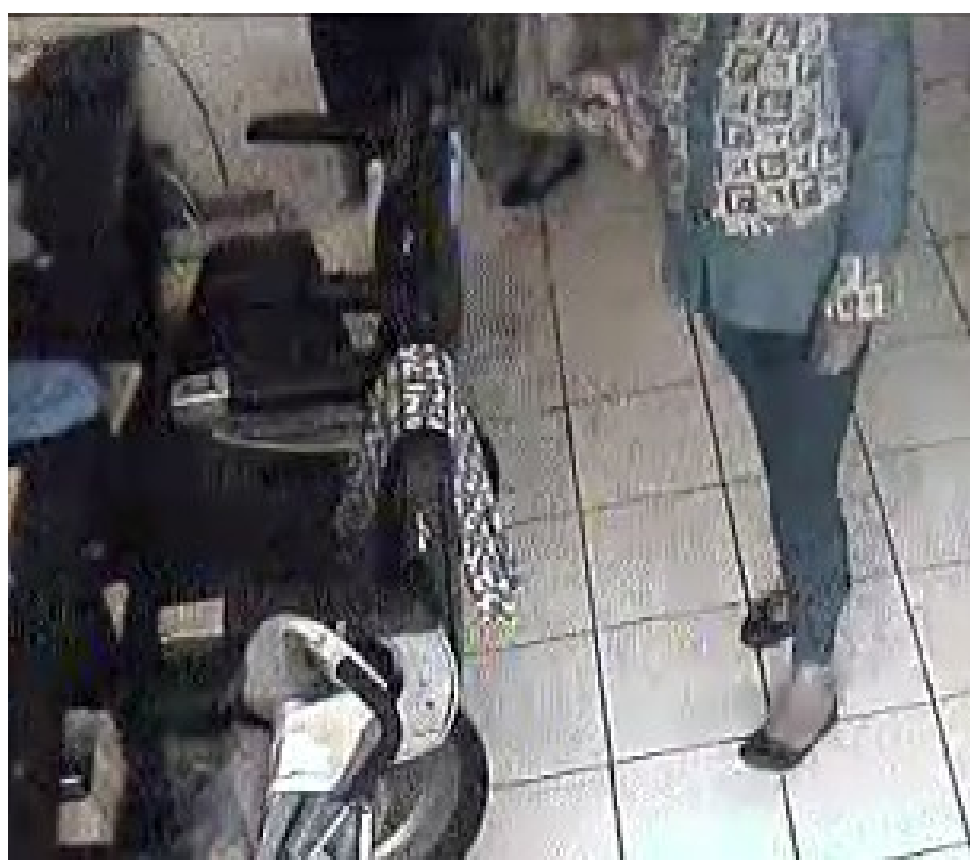

Fig. 5 Hairdresser's, Deptford.

Fig. 6 Nail shop and parlour, Deptford.

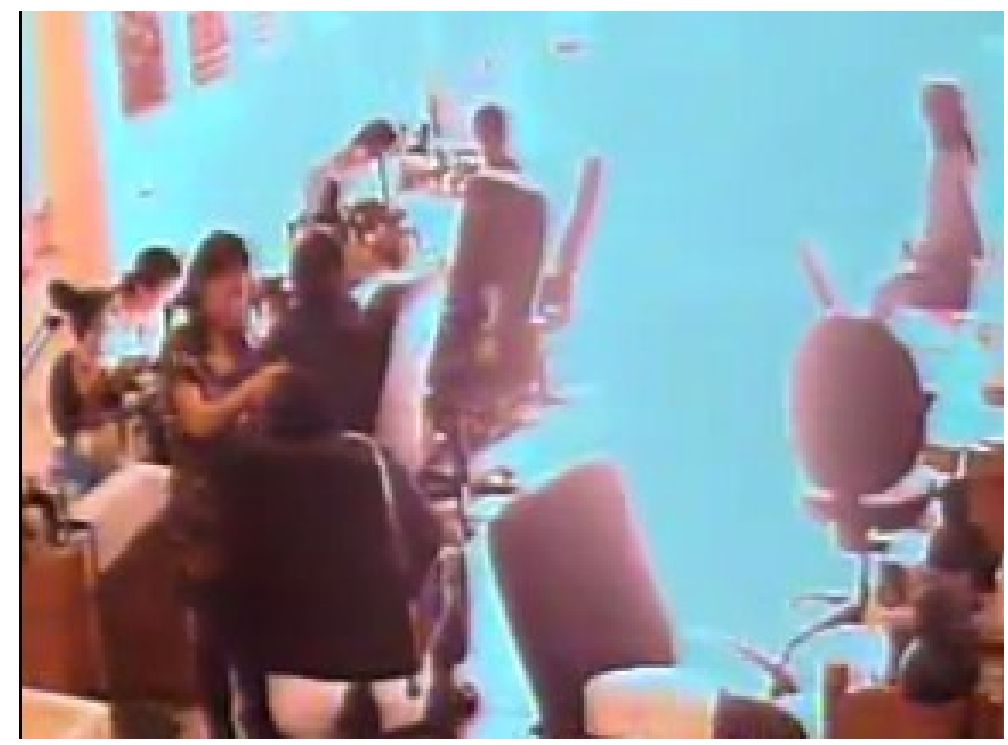




\section{Coding the 'Code of Practice'}

I participated in such workshops as a practitioner hacker and a scholar interested in the process of urban change of inner city London. At the time, my Ph.D. thesis on the gentrification of the nearby neighbourhood of East Greenwich was taking shape with the production of two photobooks printed on demand. In those, I thoroughly address methodological issues connected to the practice of walking, photographing and encountering people/participants. My endeavour aims to reach what I call a 'haptic bond' with and a multisensorial knowledge of the landscape under study (Cardullo 2011; Cardullo 2009). It is with this acquired expertise and with a reflexive motivation that I now address methodological and ethical issues of the 'video sniffing' workshops.

Obviously there are ethical issues in looking over the lives and work of others who are unaware of being recorded. These were soon by-passed in a typically pragmatic hackers' fashion: 'It is a grey area, too complicated. Let's just do it'. Sometimes a sort of revanchist attitude seemed to prevail: 'If they can take images of us, why can we take images of them?'. At the end, however, the collective decided to lock up the raw database for password enabled users. The final output would instead be published on the Internet under the responsibility of the individual or group who edited it.

For the purpose of this article, I want to dig this matter further. Looking at the Research Ethics Code of the IVSA, ${ }^{11}$ I understand that there are limitations to the use of such a practice which, at its worse, might be seen as being 'deceptive' and 'intrusive'. However, I want to maintain a pragmatic attitude here and valuing the content shown in the article, as well as the content published on the Internet by various 'sniffing' practitioners, in the context of its research exercise. In my view, the video 'sniffing'

11 Available at: http://visualsociology.org/about/category/content.html (see also Papademas et al 2009). 
workshops have not been harmful to the subjects of the research. The ethos of this article is in fact to portray those involuntary participants in a positive light. Moreover, the scope and the techniques of the research are effective in producing a certain output because they do use undercover recordings, showing workers' interactions in their daily space. Such places are also framed in this article as 'contact zones', that is, they are significant to the extent they are thought in terms of their openness to the public. In this sense, shops can be thought as semi-public spaces in which a certain amount of public life is enacted. Finally and crucially, this unusual technique of gathering data has not infringed the privacy of the subjects portrayed. Hardly any face is ever shown simply because cameras are positioned outwards, towards potential intruders, or from above. That is, no personal data is collected because people in the films remain anonymous. Other media artists pushed forth ethical issues of privacy in the age of wireless digital technologies and social media sharing practices. They have gone further down the legal path claiming back, on privacy grounds, their own images from corporate surveillance cameras. Artist Manu Luksh, for instance, is known to have sent forms with an attached cheques to companies, requesting a dvd with her own face at that moment of the day when she was passing by that precise spot covered by specific CCTV cameras. ${ }^{12}$ All other faces had to be digitally removed with large black dots. Her movie 'Faceless' recalls a dystopian world out of the best science-fiction tradition and it is made by the exclusive use of other people's surveillance cameras.

That said, I want to recall that it is not the first time that 'realistic' attempts to record everyday life in the streets have given way to controversial ethical outcomes. Our practice-based approach reminds me of some aspects of the Mass-Observation research project. In the inter-war period observers were sent through the streets of Bolton to overlook working-class people's attitudes. Volunteers kept diaries, and sometimes took photographs, while observation was carried out in the streets so that 12 See for instance "Faceless" by Manu Luksch (2006) http://vimeo.com/307940 
the mass collective unconsciousness of intimate people's lives would eventually come out (Jeffery 1999). ${ }^{13}$ On a similar page, but with a different aim, W. H. White deployed assistant researchers with cameras, 'often mounted on construction scaffolds or positioned in rooms of deserted hotels', attempting 'to remain unobserved' (Harper 2012, 71).

What appeared certain to most participants of the 'sniffing' workshops was that CCTV cameras offer opportunity for interaction. Often practitioners and shop assistants engaged in playful dialogues and in reciprocal acting out for the surveillance cameras (Fig. 10-11). This can certainly be seen as a sort of informed consent to the recording. A so-called 'mutual gaze' with the security recording device proved not to be impossible (see Koskela 2003 for a different opinion). Without overstating the outcome of the 'sniffing' workshops, I want to emphasize moments of exchange with the technologies of video surveillance as well as with the 'watchers'. In many of these now sprawling art and media projects that make use of CCTV filming techniques, there is a sense in which practitioners are acting in front of the CCTV cameras. ${ }^{14}$ Once the signal is hacked, in fact, why not to use it for the purpose of making your own film? Video surveillance seemed to be, for these practitioners, just another fact of life to happen to be dealing with.

The second aspect I want to address here is the mix method used to making the city known, which combines 'video sniffing' and walking. One of the strengths of this practice lays exactly in their subversive indeterminacy. Clearly inspired by the praxis of

13 A discussion on the merits and limits of the Mass-Observation is beyond the scopes of this article, but it is important to connect the two experiences as they have, in my view, more than one point in common (see also Newbury 1999 for a critique).

Also in the practice of keeping diaries of the neighbourhood activity in the Sarai project in Cybermohalla. I see a tight connection between the observant at the corner of a busy junction (so called Street Logs) and the hacker of CCTV signals http://www.sarai.net/practices/cybermohalla. Both are critical of the familiar and the banal of the city from below.

14 Also in our workshops, there are naïve attempts of performing for the CCTV camera, as in the Chinese take-away clip: http://edit.deptford.tv/node/197 or in the art shop: http://edit.deptford.tv/node/208 
the Situationist International, art and media projects which use the 'video sniffing' techniques invite to disrupt the hegemonic power of capital-driven urbanism and to refresh our understanding of the city. They lead participants to explore civic relationships through play, in order to bridge personal and public space, individual and collective experience, and physical and historical condition, into a rhizomatic and generative urban drift. In De Certeau's terms, this practice resembles the 'Fall of Icarus', from the 107th floor of the World Trade Centre to the daily actions of writing the textures of such a landscape (De Certeau 1984). Walking and 'sniffing' challenge the power relationship implicit in planning, in the administrative way of surveying urban space as well as in the overwhelming practice of corporate and police video surveillance. In this sense, 'video sniffing' re-presents cities as made and re-made by the anarchic unfolding of daily experience of space, weaving a narrative which is context-based and reflexive. In other words, this innovative practice works with regards to spaces and geographies of the everyday, rather than to the macro-economic logic of urban change. This regulating logic, while destroying and creating urban space, completely overlooks space itself, in the sense of the experienced space of the very familiar city.

The hunting and hacking of CCTV signals revitalised some city spaces which none or few of us were aware of before - but in which working-class people of Deptford obviously live their everyday life, everyday. They made city for us, researchers. They reproduced yet another representation of the city. But they also became a transformative experience of self-discovery. I will argue this point in the next section, again using content analysis of videos, my own diary notes from years of participant observation of this hackers' collective, and interviews with workshop participants.

\section{'It's a bit like fishing'}

What kind of affective reactions did the encounters with video surveillance produce in 
the young practitioners? From my direct experience in three of the sniffing workshops, I recall a sense of genuine excitement at the discovery of any open signal ready to be hacked: 'It's a bit like fishing', as one participant put it. Initial curiosity and playful wonder soon gave room to cunning tactics and exchange of information between groups moving now more swiftly through the city: participants became almost addicted to following glitches and wave trails across inner London. This became evident during the workshops as an exercise of inversion. Armed with their own rudimentary devices, participants were hunting for urban video surveillance in order to play with it and challenge it. But somehow, they also became haunted by them. This is another reason why 'video sniffing' is not as simple as a deceptive undercover observation, rather it could be a meaningful ethnographic exercise.

In this practice there is very little of a detached and purified act of vision. What could have been possible in the confined and homogeneously built prison of Bentham's dreams escaped, in our experience of wonder and discovery, through the remote corners of inner-city Deptford. The bright environment of the modern prison had left room to the penumbra of the post-modern search for meanings between readily available appearances and more uncanny and introspective insights of the city many pasts. The short films produced from the workshops maintain this element of suspension and dream-like status, in-between glitches and ghostly manifestations of the hacked signals. ${ }^{15}$ Realistic life scenarios suddenly materialised from the uncertain waves and scratches of the audio-visual reception on the recording device, as from the depth of unconscious dreams (Fig. 7-9). Such spectral manifestations left a very uncanny feeling in most of participants' imaginary, some speaking of 'ghostly trail', others of 'appearances', a sort of Derridean 'ghostly dance'. ${ }^{16}$

15 Watch the fine short film 'A Trail of Images' (2009) by A. Hadzi, with music by R. Canning, which uses a montage of glitches and interferences from the raw recordings: http://tinyurl.com/c5hk2bw

16 See Derrida speaking of the ghostly affordances of media in the film 'Ghost Dance' (McMullen 1983): 'technology of images and telecommunication enhances the power of 

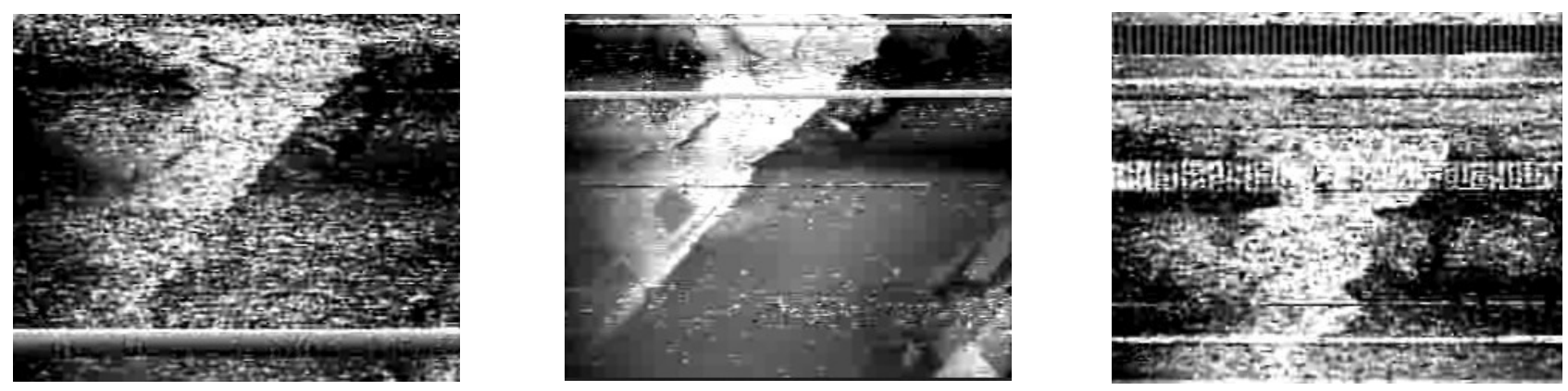

Fig. 7-9 from 'A Trail of Images' (Hadzi et al. 2009).

Nor it is the case that CCTV filming practice might have given room to eccentric and distant, flâneur-like exploration of the city. Despite the recording device could pick up signals many metres away from its source, it was in fact participants' intention to interact with the cameras and make their presence visible in the new spaces discovered by the sniffing practice. In order to do that, they often had to encounter people from 'behind' the surveillance cameras, sometimes being curious shop assistants or suspicious property owners. When such encounters materialised, it was necessary to give explanations on the aims of the project. For De Certeau, encounters form a sort of contract between the walker and other people. Walking is a bit like 'spaces of enunciation' which imply a referent, somebody to talk to. Encounters can become the unplanned and generative way of making space and producing 'fieldwork' (de Certeau 1984, pp.97-99).

Another way to put this is to argue for the paradoxical character of the flâneur. S/He puts at the centre of knowledge the act of seeing. However, by the very act of walking the flâneur contradicts this centrality, hinging on all the other senses and their interconnections. Walking defies seeing as a detached and purified way of knowing. Rather, it recasts seeing as a multisensorial bond with the landscape. In this sense, the flâneur stands for a 'metaphor of methods' (Jenks 1994, p.148). This metaphor is an

ghosts and their ability to haunt us' 
attitude towards knowledge. Its social context is grounded in the everyday movement through the urban landscape. It stands for a cognitive behaviour which is at the core of a realist epistemology. I therefore suggest that the 'video sniffing' is a middle-way tool between the detached experience of the flâneur and the heroic ethnographic immersion.

Rather than abandoning themselves into an indulgent technological determinism, practitioners relied on their own eyes, ears and social skills to identify and record evidence of covert signals. Other senses were set in motion and stimulated by the act of walking with the camera (see also Pink, 2007, 2008). Some ordered their favourite take-away meal while recording. Walking and photographing are 'combined practices' (Cardullo 2011) which work together, stimulating observers' sensorial understanding of the city to a higher level. Exchange of local knowledge and of open wireless spots between groups was also an important way of networking in the field. Groups returned to the same camera at different time of the day or even during subsequent workshops.

Excitement, wonder, frustration, joy, curiosity, worry, trust or diffidence were some of the affective reactions that our psychogeography and the encounters which determined were able to circulate. Participants did not just recreate the city through the editing of the raw clips, but they also felt it in a way that they had rarely experienced before. To a certain extent, they became part of those very narratives they were trying to disentangle. 


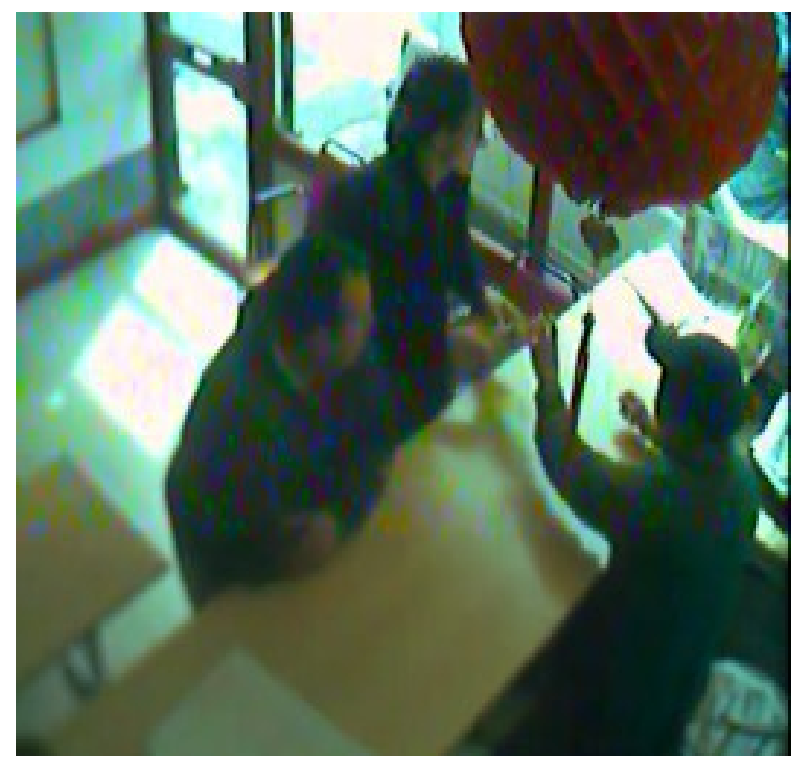

Fig. 10 Participant enters a Chinese take-away and asks for menu, Deptford.

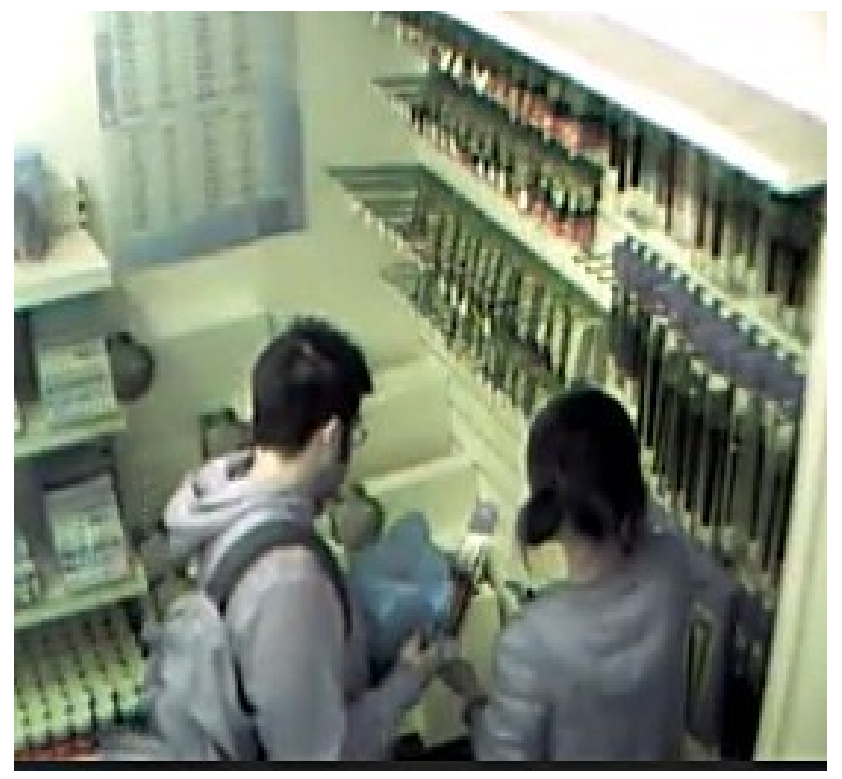

Fig. 11 Participant enters an art shop and asks for paint brush, Greenwich.

\section{Concluding Remarks}

In this article I outlined some methodological insights around what it could be another research tool for browsing the messiness of urban living, what I called 'video sniffing' practice. This is a combination of walking through the city, with De Certeau and the Situationist derivé in mind, and the skilful hacking of commonly available video 
recording devices. I narrated the scoping and the background in which such workshops took place, giving contextual nuances to our urban immersions in inner city London. I argued that the content of the videos captured from lower-end CCTV cameras are significant in juxtaposition to bolstering and benevolent narratives of gentrification. With the help of some critical scholars, I suggested that this predominant discourse on urban change, while pushing forth a much celebrated middle-class lifestyle, falls very short of acknowledging the spaces in which everyday working-class practices of work, leisure and socialisation are enacted. In other words, this narrative of gentrification speaks as if the middle-classes were the only subject in town (see also Slater 2006).

My contention is that the video output of these workshops might indeed help us to reflect upon the invisibility of displacement. If working-class displacement is about 'mapping the invisible' (Atkinson and Bridge 2005), how do we prove it? Possible answers are to be found in the spaces of the mundane, far too often overlooked as banal and uninteresting. There, the relevance of use-value over exchange-value can be exposed, and a crucial critique of value can be developed. It is in this often neglected space that the effects of the forces and dynamics of abstractions, such as 'capitalism', 'gentrification', or 'displacement' become realities in the lives of social agents who directly experience the effects of these forces on themselves.

Finally, these workshops were an exercise of knowing the city through mechanical (or rather digital) eyes, which belong to others and are set in place for reasons other than the scoping suggested by our research. ${ }^{17}$ Their outcome was a collaboration and a negotiation between hackers - who tried to invert the relationship between watchers and watched in their search of the overarching structure of the panopticon society and urban scholars and practitioners - who were in search of yet another experimental method of making city entanglements alive. Is this exercise ethic? I tried to answer collaboration with the CAST at the University of Copenhagen (Cardullo 2013). 
above by keeping in mind the very important guidelines and principles offered by the IVSA Research Ethic Code. I approached ethical issues in a holistic and pragmatic sense arguing that, like the kernel of a computer system, this Code too can be toggled, hacked, rewritten and adjusted to the never ending situations and experiments that innovative technologies and forthcoming visual practices might require. ${ }^{18}$ Will or should 'video sniffing' be considered as an innovative practice in Visual Sociology? Would this method advance our understanding of society? What I offered here is an almost unique (because of the unusual tool deployed) insight into the life of an inner-city neighbourhood. This research exercise also reflects upon the ever changing technology of visual recording. It is deeply conditioned by some people's ability to work around, that is 'to hack', such changes. Hackers' and media artists often offer experimental endeavours at the margin of our growing and interdisciplinary field of study. These endeavours, I would argue, are interesting and informing to the extent that more established scholars can make sense of their modest but creative dimensions.

18 Anthropologist Gabriella Coleman has recently completed her long-term research on hackers communities around the Linux Debian project in San Francisco. She states: 'For a hacker law is code; legal reform is just another hack' (Coleman 2012). 


\section{References}

Allen, Chris. 2008. "Gentrification 'Research' and the Academic Nobility: A Different

Class?" International Journal of Urban and Regional Research 32 (1) (March 1): 180-185. doi:10.1111/j.1468-2427.2008.00770.x.

Atkinson, R., and G. Bridge. 2005. Gentrification in a Global Context: The New Urban Colonialism. Routledge.

Back, Les. 2009. "Researching Community and Its Moral Projects." Twenty-First Century Society 4 (2) (June): 201-214. doi:10.1080/17450140903000316.

Back, Les, and Dawn Lyon. 2012. "Fishmongers in a Global Economy: Craft and Social Relations on a London Market." Sociological Research Online 17 (2): 23.

Becker, Howard. 2002. "Visual Evidence: A Seventh Man, the Specified Generalization, and the Work of the Reader." Visual Studies (17): 3-11.

Cardullo, Paolo. 2009. Walking on the Rim: a Tale of Abjection. London: Blurb. http://kiddingthecity.org/blog/?p=963.

_ 2011. Walking on the Rim: Photos, Encounters, Objects. London: Blurb. http://kiddingthecity.org/blog/?p=1287.

_ 2013. "'Can You See Me? I Can See You!' Issues of Sousveillance." In Visual Aspect of Security. CAST - University of Copenhagen. Routledge.

Coleman, E. Gabriella. 2012. Coding Freedom: The Ethics and Aesthetics of Hacking. Princeton University Press.

Davidson, Mark. 2009. "Displacement, Space and Dwelling: Placing Gentrification Debate." Ethics, Place \& Environment 12 (2) (June): 219-234. doi:10.1080/13668790902863465.

Davidson, Mark, and Loretta Lees. 2005. “New-Build 'Gentrification' and London's Riverside Renaissance." Environment and Planning A 37 (7): 1165 - 1190. doi:10.1068/a3739. 
Gabrys, Jennifer. 2011. Digital Rubbish: A Natural History of Electronics. Ann Arbor: University of Michigan Press.

Hall, Stuart, and Les Back. 2009. "At Home and Not at Home: Stuart Hall in Conversation with Les Back." Cultural Studies 23 (4) (July): 658-687. doi:10.1080/09502380902950963.

Hamnett, Chris. 2003. "Gentrification and the Middle-class Remaking of Inner London, 1961-2001." Urban Studies 40 (12) (November): 2401-2426. doi:10.1080/0042098032000136138.

Harper, Douglas. 2012. Visual Sociology. London: Routledge.

Jeffery, Tom. 1999. Mass-Observation: A Short History. New ed. Brighton: MassObservation Archive University of Sussex Library.

Keith, Michael. 2005. After the Cosmopolitan?: Multicultural Cities and the Future of Racism. 1st ed. New York, NY: Routledge.

Knowles, Caroline, and Paul Sweetman. 2004. Picturing the Social Landscape: Visual Methods in the Sociological Imagination. New York: Routledge.

Lees, Loretta. 2008. "Gentrification and Social Mixing: Towards an Inclusive Urban Renaissance?" Urban Studies 45 (12) (November 1): 2449-2470. doi:10.1177/0042098008097099.

Marcuse, Peter. 1985. "Gentrification, Abandonment, and Displacement: Connections, Causes, and Policy Responses in New York City." Washington University Journal of Urban and Contemporary Law 28: 195.

Margulies, Ivone. 1996. Nothing Happens: Chantal Akerman's Hyperrealist Everyday. Durham: Duke University Press.

McMullen, Ken. 1983. "The Science Of Ghosts" - Derrida In "Ghost Dance." http://tinyurl.com/623wj98.

Newbury, Darren. 1999. "Photography and the Visualization of Working Class Lives in Britain." Visual Anthropology Review 15 (1). American Anthropology 
Association.

Papademas, Diana, and the International Visual Sociology Association. 2009. "IVSA Code of Research Ethics and Guidelines." Visual Studies 24 (3): 250-257. doi:10.1080/14725860903309187.

Pink, Sarah. 2007. "Walking with Video." Visual Studies 22 (3) (December): 240-252. doi:10.1080/14725860701657142.

Prosser, J. 2005. "The Moral Maze of Image Ethics." In Ethics and Research in Inclusive Education: Values into Practice. London: Routledge, 133-148.

Silverman, Emily, Ruth Lupton, and Alex Fenton. 2006. "A Good Place for Children? Attracting and Retaining Families in Inner Urban Mixed Income Communities". London: Rowntree Foundation.

Slater, Tom. 2006. "The Eviction of Critical Perspectives from Gentrification Research." International Journal of Urban and Regional Research 30 (4): 737-757.

—. 2009. "Missing Marcuse: On Gentrification and Displacement." City 13 (2) (June): 292-311. doi:10.1080/13604810902982250.

Wacquant, L. 2008. "Relocating Gentrification: The Working Class, Science and the State in Recent Urban Research." International Journal of Urban and Regional Research 32 (1) (March 1): 198-205. doi:10.1111/j.1468-2427.2008.00774.x. 